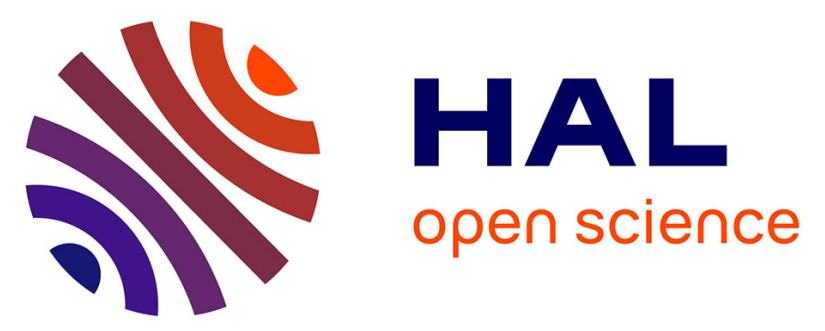

\title{
Associations between Resting, Activity, and Daily Metabolic Rate in Free-Living Endotherms: No Universal Rule in Birds and Mammals
}

Steven J Portugal, Jonathan A Green, Lewis G Halsey, Walter Arnold, Vincent Careau, Peter Dann, Peter B Frappell, David Grémillet, Yves Handrich, Graham R Martin, et al.

\section{To cite this version:}

Steven J Portugal, Jonathan A Green, Lewis G Halsey, Walter Arnold, Vincent Careau, et al.. Associations between Resting, Activity, and Daily Metabolic Rate in Free-Living Endotherms: No Universal Rule in Birds and Mammals. Physiological and Biochemical Zoology, 2016, 89 (3), pp.251-261. 10.1086/686322 . hal-03561726

\section{HAL Id: hal-03561726 https://hal.science/hal-03561726}

Submitted on 8 Feb 2022

HAL is a multi-disciplinary open access archive for the deposit and dissemination of scientific research documents, whether they are published or not. The documents may come from teaching and research institutions in France or abroad, or from public or private research centers.
L'archive ouverte pluridisciplinaire HAL, est destinée au dépôt et à la diffusion de documents scientifiques de niveau recherche, publiés ou non, émanant des établissements d'enseignement et de recherche français ou étrangers, des laboratoires publics ou privés. 
Published in " Physiological and Biochemical Zoology"

\section{Associations Between Resting, Activity and Daily metabolic rate in Free-living Endotherms: No Universal Rule in Birds and Mammals}

Steven J. Portugal ${ }^{1}$, Jonathan A. Green ${ }^{2}$, Lewis G. Halsey ${ }^{3 *}$, Walter Arnold ${ }^{4}$, Vincent Careau ${ }^{5}$, 5 Peter Dann ${ }^{6}$, Peter B. Frappell ${ }^{7}$, David Grémillet ${ }^{8}$, Yves Handrich ${ }^{9}$, Graham R. Martin ${ }^{10}$, Thomas Ruf $^{4}$, Magella M. Guillemette ${ }^{11}$ and Patrick J. Butler ${ }^{10}$

${ }^{1}$ School of Biological Sciences, Royal Holloway, University of London, Egham, Surrey, TW20 0EX

${ }^{2}$ School of Environmental Sciences, University of Liverpool, Liverpool, UK, L69 3GP, UK

${ }^{3}$ Department of Life Sciences, University of Roehampton, London, SW15 4JD, UK

$10{ }^{4}$ Research Institute of Wildlife Ecology, University of Veterinary Medicine Vienna, Savoyenstrasse 1, 1160, Vienna, Austria

${ }^{5}$ Department of Biology, University of Ottawa, Ottawa, ON, Canada, K1N 6N5

${ }^{6}$ Research Department, Phillip Island Nature Parks, P.O. Box 97, Cowes, Victoria, 3922, Australia

${ }^{7}$ School of Zoology, University of Tasmania, Hobart, Tasmania, 7001, Australia

$15{ }^{8}$ Centre d'Ecologie Fonctionnelle et Evolutive, UMR 5175, CNRS - Université de Montpellier - Université Paul-Valéry Montpellier - EPHE, Montpellier, France. Second address : Percy FitzPatrick Institute, DST/NRF Centre of Excellence, University of Cape Town, Rondebosch 7701, South Africa

${ }^{9}$ Centre d'Ecologie et Physiologie Energétiques, Centre National de la Recherche Scientifique, Strasbourg, France

${ }^{10}$ School of Biosciences, The University of Birmingham, Edgbaston, Birmingham, UK, B15 2TT, UK

${ }^{11}$ Départment de Biologie et Géographie, Université du Québec à Rimouski, Rimouski, Canada

*Corresponding author, e-mail: 1.halsey@ roehampton.ac.uk

Keywords: energy management model; energy expenditure, heart rate, intra-specific, oxygen consumption

Running page head: Metabolic rates in free-living endotherms 
What is already known: Inter-specific studies show some inconsistent evidence for a relationship between basal or resting metabolic rate and daily metabolic rate in wild animals. From these findings some tentative interpretations can be made about underlying drivers. Intra-specific studies looking at such patterns are sparse and consider only single species.

What this study adds: The first intra-specific analysis for multiple species (birds and mammals), including investigation of relationships not only between resting energy expenditure and daily energy expenditure but also with activity-specific energy expenditure. This additional metric of metabolic rate enables analysis of the energy management strategy used by different species in the wild, and uncovers key differences between birds and mammals. 


\section{ABSTRACT}

Energy management models provide theories and predictions for how animals manage their energy budgets within their energetic constraints, in terms of their resting metabolic rate (RMR) and daily energy expenditure (DEE). Thus uncovering what associations exist between DEE and RMR are key to testing these models. Accordingly, there is considerable interest in the relationship between DEE and RMR at both inter- and intra-specific levels. Interpretation of the evidence for particular energy management models is enhanced by also considering the energy spent specifically on costly activities (activity energy expenditure; AEE $=$ DEE - RMR). However, to date there have been few intraspecific studies investigating such patterns. Our aim was to determine whether there is a generality of intra-specific relationships among RMR, DEE and AEE using long-term data sets for bird and mammal species. For mammals, we use minimum heart rate $\left(f_{\mathrm{H}}\right)$, mean $f_{\mathrm{H}}$ and activity $f_{\mathrm{H}}$ as qualitative proxies for RMR, DEE and AEE, respectively. For the birds we take advantage of calibration equations to convert $f_{\mathrm{H}}$ into rate of oxygen consumption in order to provide quantitative proxies for RMR, DEE and AEE. For all 11 species, the DEE proxy was significantly, positively correlated with the RMR proxy. There was also evidence of a significant positive correlation between AEE and RMR in all four mammal species but only in some of the bird species. Our results indicate there is no universal rule for birds and mammals governing the relationships among RMR, AEE and DEE. Furthermore, they suggest that birds tend to have a different strategy for managing their energy

60 budgets to mammals, and that there are also differences between bird species. Future work in laboratory settings or highly controlled field settings can tease out the environmental and physiological processes contributing to variation in energy management strategies exhibited by different species. 


\section{INTRODUCTION}

Knowledge of energy budgets underlies our understanding of processes operating at every level of biological organisation from the sub-cellular to entire communities. At the whole organism level, energy use is typically quantified in terms of daily energy expenditure (DEE, a proxy for the mean daily energy expenditure of a free-living animal), or basal metabolic rate (BMR, the metabolic rate of an inactive adult non-reproductive post-absorptive endotherm in its thermoneutral zone). Data for rates of energy expenditure, including DEE and BMR, are now available for over 1000 species of birds and mammals (McNab 2008, 2009; Speakman and Król 2010). At the intra-specific (interindividual) level, these rates of energy expenditure have been related to other measures such as behaviour, reproductive output, fitness and survival (Artacho and Nespolo 2009; Blackmer et al. 2005; Bochdansky et al. 2005; Boratyński et al. 2010; Jackson et al. 2001; Larivée et al. 2010). Meanwhile at the inter-specific level, variation in these rates have been hypothesised to underlie a range of ecological patterns (Allen et al. 2002; Brown et al. 2004; Buckley et al. 2008; Meehan 2006; Meehan et al. 2004; Munch and Salinas 2009). As such there has been considerable interest in the effect of broad-scale environmental characteristics on both DEE and BMR (e.g. Anderson and Jetz 2005; Humphries et al. 2005; Jetz et al. 2007; Lovegrove 2003; McNab and Morrison 1963; Mueller and Diamond 2001; Speakman and Król 2010; White et al. 2007). For example, these inter-specific comparative studies have revealed that both BMR and DEE are negatively associated with mean habitat temperature.

There is also interest in the relationship between DEE and BMR (Daan et al. 1990; Koteja 1991; Ricklefs et al. 1996; White and Seymour 2004). Once the effect of body mass is accounted for, BMR and DEE are positively correlated across eutherian mammals but not significantly correlated across birds or across marsupials (Koteja 1991; Ricklefs et al. 1996; White and Seymour 2004). Intra-specific studies of the relationship between DEE and BMR are less common because both of these quantities have only been measured on the same individuals for a small number of species. Collectively, these investigations yielded equivocal results regarding the relationship 
between DEE and BMR. While some studies reported a significant correlation between DEE and BMR (Nilsson 2002; Rezende et al. 2009; Tieleman et al. 2008), other studies reported a nonsignificant correlation after correcting for various intrinsic and extrinsic factors (Fyhn et al. 2001; Meerlo et al. 1997; Peterson et al. 1998; Speakman et al. 2003). Moreover, some studies found that the association between DEE and BMR can change from one context to another. For example, DEE and RMR were positively correlated in free-living chipmunks during the reproductive season, but this correlation did not persist during other periods of the year (Careau et al. 2013). The opposite was found in captive zebra finches, where DEE and RMR were positively correlated at the nonbreeding stage, but not correlated during reproduction (at the one-egg stage, the relationship is dependent on the context under which it is examined, i.e., reproductive season: Careau et al. 2013; Vezina et al. 2006).

Our understanding of how animals manage their energy budget assuming they have energetic constraints is intimately linked to the way in which DEE and RMR relate to each other at the intraspecific level. Yet significant insight may be gained by not only looking at BMR (or RMR) and DEE of an animal, but also the energy spent specifically on energetically costly activities (Ricklefs et al. 1996). This quantity can be described as AEE (Activity Energy Expenditure; AEE = DEE - RMR; White et al. 2011). Considering RMR, DEE, and AEE allows us to distinguish among three different conceptual models of energy budgets:

- The 'performance model' (Careau et al. 2008). (Also referred to as the increased-intake hypothesis; Nilsson 2002). This model assumes that the capacity to expend energy at a high rate during activity requires greater maintenance costs (i.e., AEE and RMR should be positively correlated). In this case, higher RMR is predicted to be positively related to DEE with a slope >1 (Mathot and Dingemanse 2015).

- The 'allocation model' (Careau et al. 2008) sets DEE as a fixed amount and thus it does not vary with RMR, while AEE decreases with increasing RMR. In this case, the slope of the DEE-RMR relationship is predicted to be zero (Mathot and Dingemanse 2015). 
- Finally, the 'independent model' (Careau and Garland Jr. 2012) describes RMR and AEE as independent of each other such that, for example, increases in RMR do not result in changes to energy spent on other processes. Increases in RMR are nonetheless predicted to have a positive relation with DEE since the former is a component of the latter, but with a slope no greater than unity since there is no relationship between RMR and AEE (Mathot and Dingemanse 2015).

An example of the application of such analysis is demonstrated in a study of Australasian gannets Morus serrator by Green et al. (2013), using heart rate $\left(f_{\mathrm{H}}\right)$ as a calibrated proxy for metabolic rate. The positive correlation between $\mathrm{RMR}$ and $\mathrm{DEE}$ in this species reflects variation in the magnitude of RMR, but there is no variation in AEE with RMR, suggesting the independent model of energy management. These findings for gannets contrast with the only comparable inter-specific study, in which Ricklefs et al. (1996) found that birds showed no significant correlation between BMR and DEE as well as no significant correlation between BMR and AEE, whereas mammals showed a positive correlation between BMR and both DEE and AEE. However, whether the findings of inter-specific studies are comparable to those of intra-specific studies is questionable. Certainly, if we wish to study the consistency/variability of relationships across species, comparisons must be made of multiple intra-specific analyses.

In the present study, we expand on the limited intra-specific data previously analysed and examine the generality of the relationships among RMR, AEE, and DEE using long-term data sets for seven species of bird and four species of mammal. We investigate whether the strategy of energy management differs within or between these two taxa. Each of these data sets uses heart rate $\left(f_{\mathrm{H}}\right)$ as a proxy for metabolic rate, since heart rate and rate of oxygen consumption $\left(\dot{V}_{\mathrm{O}_{2}}\right)$ have been shown

140 to be positively correlated in every endothermic species examined so far (Green 2011), in accordance with Fick's principle (Fick 1870). For birds we use a quantitative approach (see Green 2011) since $\dot{V}_{\mathrm{O}_{2}}-f_{\mathrm{H}}$ calibrations were available for each species, and also report the output resulting from the 
qualitative approach for comparative purposes. For mammals we used a qualitative approach (see Green 2011) where directional trends in $f_{\mathrm{H}}$ are used to infer directional trends in $\dot{V}_{\mathrm{O}_{2}}$.

\section{METHODS}

Heart rate was measured continuously using surgically implanted heart rate data loggers or transmitters, or by ruminal devices administered orally (Signer et al. 2010), employed primarily to investigate other research questions. In total, data sets from seven bird and four mammal species were available for analysis (Table 1). Information and details regarding the devices used, implantation and removal procedures, and data collection protocols are available from the following sources; great cormorants Phalacrocorax carbo (Grémillet et al. 2005), barnacle geese Branta leucopsis (Portugal et al. 2009), Australasian gannets (Green et al. 2013), little penguins Eudyptula minor (J.A. Green, L.R. Horne, P. Dann, P.J. Butler \& P.B. Frappell, unpublished data), king penguins Aptenodytes patagonicus (Halsey et al. 2010), macaroni penguins Eudyptes chrysolophus (Green et al. 2009), eider ducks Somateria mollissima (Guillemette et al. 2007), Przewalski horses Equus ferus przewalksii (Arnold et al. 2006), alpine ibex Capra ibex (Signer et al. 2011), red deer Cervus elaphus (Turbill et al. 2011) and roe deer Capreolus capreolus (W. Arnold, F. Schober, unpublished data). For alpine ibex and red deer, heart rate was determined from an accelerometer located in the reticulum, which accurately recorded heart rate when the instrumented animal was stationary and during relatively gentle activity. At higher levels of activity, however, heart rate was not discernible in the recorded acceleration data, and thus heart rate at high levels of activity is not included in the data sets for these two species.

For all individuals of each species, mean daily heart rate was calculated for each day (i.e., for each $16524 \mathrm{~h}$ period), while minimum daily heart rate was determined by calculating mean $f_{\mathrm{H}}$ for consecutive short time intervals (5-15 min depending on study) throughout the day and selecting the lowest of these values for each day. Activity daily $f_{\mathrm{H}}$ was then calculated as the difference between mean daily 
$f_{\mathrm{H}}$ and minimum daily $f_{\mathrm{H}}$. A grand mean of all individuals was then calculated for each day of each study for all three variables. As the data are mean measures of heart rate from successive days, the degree of serial autocorrelation in the data was assessed prior to all statistical tests. The autocorrelation function in Minitab (Mintab Inc.) indicated, for each species, the number of data points between values of mean daily $f_{\mathrm{H}}$, minimum daily $f_{\mathrm{H}}$ and activity daily $f_{\mathrm{H}}$ required to produce non-significant levels of autocorrelation, i.e. the minimum interval necessary for time series data to be independent. We then calculated means of each of the three variables for time periods equal to the 175 largest of these three intervals for each species (see Table 1) to give the following three variables: mean $f_{\mathrm{H}}, \min f_{\mathrm{H}}$ and activity $f_{\mathrm{H}}$. For birds, mean $f_{\mathrm{H}}$ and $\min f_{\mathrm{H}}$ were converted into estimates of mean $\dot{V}_{\mathrm{O}_{2}}$ and $\min \dot{V}_{\mathrm{O}_{2}}$ respectively, using calibration equations from the following sources: great cormorants (White et al. 2011), barnacle geese (Portugal et al. 2009), Australasian gannets (Green et al. 2013), little penguins (Green et al. 2008), king penguins (Halsey et al. 2007), macaroni penguins

180 (Green et al. 2000), common eiders (Hawkins et al. 2000) and, where necessary, animal masses reported therein. Activity $\dot{V}_{\mathrm{O}_{2}}$ was given as min $\dot{V}_{\mathrm{O}_{2}}$ subtracted from mean $\dot{V}_{\mathrm{O}_{2}}$. Therefore for birds, mean $\dot{V}_{\mathrm{O}_{2}}$, min $\dot{V}_{\mathrm{O}_{2}}$ and activity $\dot{V}_{\mathrm{O}_{2}}$ were quantitative proxies for DEE, RMR and AEE, respectively, while for mammals, mean $f_{\mathrm{H}}, \min f_{\mathrm{H}}$ and activity $f_{\mathrm{H}}$ were qualitative proxies for DEE, RMR and AEE, respectively. Simple linear regressions conducted in SPSS v.21 (IBM Inc.) examined the 185 relationships between $\min f_{\mathrm{H}}$ and mean $f_{\mathrm{H}}$, between $\min f_{\mathrm{H}}$ and activity $f_{\mathrm{H}}$, between min $\dot{V}_{\mathrm{O}_{2}}$ and mean $\dot{V}_{\mathrm{O}_{2}}$, and between min $\dot{V}_{\mathrm{O}_{2}}$ and activity $\dot{V}_{\mathrm{O}_{2}}$. The $\mathrm{P}$ value associated with these tests is interpreted as a continuous variable indicating the strength of evidence against the null hypothesis (Fisher 1959; Halsey et al. 2015; Lew 2012).

190 These analyses have taken advantage of the $\dot{V}_{\mathrm{O}_{2}}$-fH calibration equations available for all species of bird in the present study. For two of the bird species (great cormorants and Australasian gannets) 
these calibrations account for the curvilinear relationships in $\mathrm{fH}$ and $\dot{V}_{\mathrm{O}_{2}}$ observed in flying birds (White et al, 2011, Green et al 2013). However it has not yet been possible to account for this in the calibration equations available for barnacle geese or eider, despite knowing that calibrations based on walking may not accurately estimate $\dot{V}_{\mathrm{O}_{2}}$ from fH during flight in the geese at least (Ward et al. 2002). There is thus an argument to analyse $\mathrm{fH}$ data for birds instead. To investigate this we repeated the $\dot{V}_{\mathrm{O}_{2}}$-based analysis for birds on the underlying heart rate data (Appendix 1).

\section{RESULTS}

200 Table 1 provides full details on the results of statistical analyses undertaken in this study. The duration of data collection varied between species from a few weeks to over two years. Conducting the statistical analysis on data for each species reduced to the size of the smallest data set did not change the overall findings of the study and thus the statistical analyses reported here are based on the full data set available for each species. For all 7 bird species, there was strong evidence that mean $\dot{V}_{\mathrm{O}_{2}}$ was positively related to min $\dot{V}_{\mathrm{O}_{2}}$ (Figure 1a), while in all 4 mammal species there was strong evidence that mean $f_{\mathrm{H}}$ was positively related to $\min f_{\mathrm{H}}$ (Figure $1 \mathrm{c}$ ). Only the data for macaroni penguins indicated strong evidence for a relationship between activity $\dot{V}_{\mathrm{O}_{2}}$ and min $\dot{V}_{\mathrm{O}_{2}}$, while there was some evidence for such a relationship in the little penguin data (Figure 1b). For all other bird species there was no evidence of such a relationship. Analysing the fH data for birds, i.e. using the qualitative approach, yielded broadly similar results with only one exception (Appendix 1). All four mammal data sets provided strong evidence of a positive relationship between activity $f_{\mathrm{H}}$ and $\min f_{\mathrm{H}}$ (Figure 1d). 


\section{DISCUSSION}

The present study shows that qualitative $\left(f_{\mathrm{H}}\right)$ and quantitative $\left(\dot{V}_{\mathrm{O}_{2}}\right)$ proxies of resting metabolic rate (RMR) and daily energy expenditure (DEE) are positively related at the intra-specific level in all species of bird and mammal for which data are available (Table 1; Figure 1a and c). This provides evidence that a relationship between RMR and DEE is a consistent feature of endothermic species. The present study also shows that there is a positive intra-specific relationship between qualitative proxies of RMR and activity energy expenditure (AEE) in all examined mammals (Table 1; Figure 1d). In contrast, for five of the seven species of bird examined in the present study there was no evidence for a relationship between estimated RMR and AEE (Table 1; Figure 1b).

Examination of the relationships between RMR, AEE and DEE offers insight into the energy management strategies employed by each species. The key to this analysis is to partition DEE into RMR and AEE in order to test for evidence supporting each of the three theorised models (independent, allocation, performance).For five species of bird analysed, the data suggest they tend to employ the independent model of energy management, however for the macaroni and little 230 penguins, there is evidence of energy management based on the performance model.

Evidence of the energy management strategy employed by each of the mammal species represented in this study can also be obtained through the analysis of the $f_{\mathrm{H}}$ data. A relationship with a slope greater than 1 between activity $f_{\mathrm{H}}$ and $\min f_{\mathrm{H}}$ supports the performance model; this was the case for all four species of mammal. Some variety in the energy utilisation model apparently

235 employed between bird species, in contrast to the consistency found within mammals, may at least in part be due to the broader taxonomic range of bird species analysed, though there was a greater range of body masses in the mammals (roe deer: $25 \mathrm{~kg}$; Przewalski horse: $300 \mathrm{~kg}$ ) than in the birds (eider ducks: $2 \mathrm{~kg}$; king penguins: $10 \mathrm{~kg}$ ). 
DEE and RMR were strongly correlated in all 11 species examined here. This is in stark 240 contrast with many previous intra-specific studies, which report non-significant results (Fyhn et al. 2001; Meerlo et al. 1997; Peterson et al. 1998; Speakman et al. 2003). Aside from one study, based on a low sample size $\left(\mathrm{n}=6, \mathrm{r} 2=0.70\right.$ in Nilsson 2002), the $r^{2}$ of all of the previously reported statistically significant correlations fall below the range observed in the present study: $r^{2}=0.20$ in Tieleman et al. (2008), $r^{2}=0.23$ in Careau et al. (2013), $r^{2}=0.35$ in Vézina et al. (2006) and $r^{2}=0.50$ 245 in Rezende et al. (2009). One noticeable difference is that our results are based on heart rate telemetry, whereas all of the studies listed above used doubly labelled water and respirometry techniques to estimate DEE and BMR. Moreover, most of the previous studies reported correlations on a massresidual basis (Careau et al. 2013 also reported statistically significant correlations on a whole-animal basis), whereas our results are not adjusted for body mass differences between individuals. Previous studies investigated correlations across individuals, whereas in the present study each data point is comprised of the same set of animals. Variation in body mass within individuals over time may well at least in part drive the relationships seen in the present study between RMR, DEE and AEE (Portugal et al. 2009).

RMR often shows substantial plasticity, and can be higher in cold-acclimated animals than warm-acclimated ones (McDevitt and Speakman 1994; McKechnie 2008; McKechnie et al. 2007; Nespolo et al. 2001; Smit and McKechnie 2010; West 1972). Similarly, DEE is negatively related to ambient temperature in some studies (e.g. Speakman 2000; Tinbergen and Dietz 1994; Weathers et al. 1996), though not in others (e.g. Humphries et al. 2005). Where both DEE and RMR are negatively associated with temperature, variation in temperature during the long periods over which heart rate measurements can be made (e.g. $24-441 \mathrm{~d}$ in the present study; Table 1) will manifest as a positive association between DEE and RMR, which might spuriously indicate use of the independent model of energy management. Indeed in macaroni penguins, which spend many months of their annual cycle continuously at sea, RMR will be higher during this period as the animals are in water rather 
than air which brings a substantial thermoregulatory challenge (Green et al. 2005). These days are likely to also be associated with high activity as birds are continually active diving and foraging. Thus both RMR and AEE are elevated due to covarying environmental circumstances rather than physiological coupling. This may also be the case to a lesser extent for little penguins, which during their winter intersperse intermittent periods of several weeks at sea with periods of several days ashore (Ritchie et al. 2010). Alternatively, temperature-dependent changes in behaviour may act to buffer or eliminate the effect of ambient temperature on DEE (Humphries et al. 2005; Speakman 2000), and these changes may act in opposition to extrinsically caused changes in RMR. In addition, substitution of the heat required for thermoregulation by the heat produced by activity introduces another potential route for compensation within AEE (Humphries and Careau 2011); see also 'substitution model' (Careau and Garland Jr. 2012). Therefore, intraspecific associations among RMR, AEE and DEE could be context dependent, as has also been suggested for the consequences of intraspecific variation in RMR (Burton et al. 2011).

Thus it is not clear if the differences observed within the birds, and between birds and mammals in the present study, result from differences among species in their (a) metabolic pathways contributing to RMR and DEE, (b) responses to environmental factors that act as extrinsic drivers of RMR and DEE, or (c) perhaps even locomotion types (all four mammals are terrestrial quadrupeds while the species of bird are either predominantly flyers or swimmers).

Complex interactions among components of energy budgets can obfuscate associations among RMR, AEE, and DEE. Moreover, even if the performance model is strongly supported at the among-individual level (i.e., slope of the DEE-RMR relationship is $>1$ ), this does not rule out the possibility that some form of allocation is occurring within individuals (see Fig. IB in Careau and Garland Jr 2015). Furthermore, AEE is often a broad category encompassing a number of behaviours including feeding, preening, fighting and various types of locomotion that can differ greatly in terms of energy expenditure, and thus further understanding of an animal's energy management strategy may be obtained by investigating the heart rate of various activity sub categories. Finally, it may be 
the case that some animals alter their energy management strategy during different periods of their breeding or life cycles. For example, during moulting the energy costs of feather production may increase the RMR of birds without affecting their AEE (as shown in eider ducks; Guillemette et al. 2007) (the independent model) while during hyperphagia before migration, as their muscles and organs grow they could in theory exhibit both an increase in RMR and a correlated increase in AEE (the performance model) (cf Guillemette and Butler 2012). Future within-species research involving 1) environmentally-controlled scenarios, 2) repeated measures of DEE and RMR on multiple individuals and during different seasons, and perhaps 3) the analysis of metabolic rate for different activity types, will be necessary to uncover any intrinsically driven physiological processes contributing to variation in these traits among and within individuals.

\section{AUTHOR CONTRIBUTIONS}

LH conducted all the statistical analyses, produced all the figures, interpreted the results and fronted the writing of the manuscript in its current format; JG conducted some preliminary analyses, interpreted the results and had considerable input to the writing of the manuscript; SP and PB also supported writing the manuscript; all coauthors provided data and commented on manuscript drafts.

\section{ACKNOWLEDGEMENTS}

We are particularly thankful for the input to this manuscript by Craig White. We are grateful to

310 Tony Woakes and Maarten Loonen for assistance with the barnacle geese data, to Frank Shober for help with roe deer data collection, and to Grégoire Kuntz and Caroline Gilbert for help with collection of the great cormorant data. For funding and ethical approvals for each species, please refer to the relevant studies. 
Allen, A.P., J.H. Brown and J.F. Gillooly. 2002. Global biodiversity, biochemical kinetics, and the energetic-equivalence rule. Science 297: 1545-1548.

Anderson, K.J., and W. Jetz. 2005. The broad-scale ecology of energy expenditure of endotherms. Ecology Letters 8: 310-318.

320 Arnold, W., T. Ruf and R. Kuntz. 2006. Seasonal adjustment of energy budget in a large wild mammal, the Przewalski horse (Equus ferus przewalskii) II. Energy expenditure. Journal of Experimental Biology 209: 4566-4573.

Artacho, P., and R.F. Nespolo. 2009. Natural selection reduces energy metabolism in the garden snail, Helix aspersa (Cornu aspersum). Evolution 63: 1044-1050.

325 Blackmer, A.L., R.A. Mauck, J.T. Ackerman, C.E. Huntington, G.A. Nevitt and J.B. Williams. 2005. Exploring individual quality: basal metabolic rate and reproductive performance in stormpetrels. Behavioral Ecology 16: 906-913.

Bochdansky, A.B., P. Grønkjær, T.P. Herra and W.C. Leggett. 2005. Experimental evidence for selection against fish larvae with high metabolic rates in a food limited environment. Marine

330 Biology 147: 1413-1417.

Boratyński, Z., E. Koskela, T. Mappes and T.A. Oksanen. 2010. Sex-specific selection on energy metabolism - selection coefficients for winter survival. Journal of Evolutionary Biology 23: 19691978.

Brown, J.H., J.F. Gillooly, A.P. Allen, V.M. Savage and G.B. West. 2004. Toward a metabolic 335 theory of ecology. Ecology 85: 1771-1789.

Buckley, L.B., G.H. Rodda and W. Jetz. 2008. Thermal and energetic constraints on ectotherm abundance: a global test using lizards. Ecology 89: 48-55.

Burton, T., S.S. Killen, J.D. Armstrong and N.B. Metcalfe. 2011. What causes intraspecific variation in resting metabolic rate and what are its ecological consequences?

340 Careau, V., and T. Garland Jr. 2015. Energetics and behavior: many paths to understanding. Trends in Ecology \& Evolution 20: 1-2.

Careau, V., and T. Garland Jr. 2012. Performance, Personality, and Energetics: Correlation, Causation, and Mechanism. Physiological and Biochemical Zoology 85: 543-571.

Careau, V., D. Reale, D. Garant, F. Pelletier, J.R. Speakman and M. Humphries. 2013. Context-

345 dependent correlation between resting metabolic rate and daily energy expenditure in wild chipmunks. Journal of Experimental Biology 216: 418-426.

Careau, V., D. Thomas, M. Humphries and D. Réale. 2008. Energy metabolism and animal personality. OIKOS 117: 641-653.

Daan, S., D. Masman and A. Groenewold. 1990. Avian basal metabolic rates: their association with

350 body composition and energy expenditure in nature. American Journal of Physiology 259: R333-

R340.

Fisher, R. 1959. Statistical Methods and Scientific Inference. Hafner Publishing, New York. Fyhn, M., G.W. Gabrielsen, E.S. Nordøy, B. Moe, I. Langseth and C. Bech. 2001. Individual Variation in Field Metabolic Rate of Kittiwakes (Rissa tridactyla) during the Chick - Rearing

355 Period. Physiological and Biochemical Zoology 74: 343-355.

Green, J. 2011. The heart rate method for estimating metabolic rate: Review and recommendations. Comparative Biochemistry and Physiology, Part A 258: 287-304.

Green, J., E. Aitken-Simpson, C.R. White, A. Bunce, P.J. Butler and P.B. Frappell. 2013. An increase in minimum metabolic rate and not activity explains field metabolic rate changes in a

360 breeding seabird. Journal of Experimental Biology 216: 1726-1735.

Green, J., A.J. Woakes, I.L. Boyd and P.J. Butler. 2005. Cardiovascular adjustments during locomotion in penguins. Canadian Journal of Zoology 83: 445-454. 
Green, J.A., I.L. Boyd, A.J. Woakes, N.L. Warren and P.J. Butler. 2009. Evaluating the prudence of parents: daily energy expenditure throughout the annual cycle of a free-ranging bird. Journal of Avian Biology 40: 529-538.

Green, J.A., P.B. Frappell, T.D. Clark and P.J. Butler. 2008. Predicting rate of oxygen consumption from heart rate while little penguins work, rest and play. Comparative Biochemistry and Physiology Part A 150: 222-230.

Grémillet, D., G. Kuntz, A.J. Woakes, C. Gilbert, J.-P. Robin, Y. Le Maho and P.J. Butler. 2005.

Year-round recordings of behavioural and physiological parameters reveal the survival strategy of a poorly insulated diving endotherm during the Arctic winter. Journal of Experimental Biology 208: 4231-4241.

Guillemette, M., and P. Butler. 2012. Seasonal variation in energy expenditure is not related to activity level or water temperature in a large diving bird. Journal of Experimental Biology 215:

375 3161-3168.

Guillemette, M., D. Pelletier, J.-M. Grandbois and P.J. Butler. 2007. Flightlessness and the energetic cost of wing molt in a large sea duck. Ecology 88: 2936-2945.

Halsey, L., D. Curran-Everett, S. Vowler and G. Drummond. 2015. The fickle P value generates irreproducible results. Nature Methods 12: 179-185.

380 Halsey, L.G., P.J. Butler, A. Fahlman, C.A. Bost and Y. Handrich. 2010. Changes in the foraging dive behaviour and energetics of king penguins through summer and autumn: a month by month analysis. Marine Ecology Progress Series 401: 279-289.

Halsey, L.G., A. Fahlman, Y. Handrich, A. Schmidt, A.J. Woakes and P.J. Butler. 2007. How accurately can we estimate energetic costs in a marine top predator, the king penguin? Zoology 110:

Humphries, M., and V. Careau. 2011. Heat for Nothing or Activity for Free? Evidence and Implications of Activity-Thermoregulatory Heat Substitution. Integrative and comparative biology 51: 419-431.

Humphries, M.M., S. Boutin, D.W. Thomas, J.D. Ryan, C. Selman, A.G. McAdam, D. Berteaux 390 and J.R. Speakman. 2005. Expenditure freeze: the metabolic response of small mammals to cold environments. Ecology Letters 8: 1326-1333.

Jackson, D.M., P. Trayhurn and J.R. Speakman. 2001. Associations between energetics and overwinter survival in the short-tailed field vole Microtus agrestis. Journal of Animal Ecology 70: 633640.

395 Jetz, W., R.P. Freckleton and A.E. McKechnie. 2007. Environment, migratory tendency, phylogeny and basal metabolic rate in birds. PLoS ONE 3: e3261.

Koteja, P. 1991. On the relation between basal and field metabolic rates in birds and mammals. Functional Ecology 5: 56-64.

Larivée, M.L., S. Boutin, J.R. Speakman, A.G. McAdam and M.M. Humphries. 2010. Associations

400 between over-winter survival and resting metabolic rate in juvenile North American red squirrels. Functional Ecology 24: 597-607.

Lew, M. 2012. Bad statistical practice in pharmacology (and other basic biomedical disciplines): you probably don't know P. British Journal of Pharmacology 166: 1559-1567.

Lovegrove, B.G. 2003. The influence of climate on the basal metabolic rate of small mammals: a

405 slow-fast metabolic continuum. Journal of Comparative Physiology B 173: 87-112.

Mathot, K., and N. Dingemanse. 2015. Energetics and behavior: unrequited needs and new directions. TREE 30: 199-206.

McDevitt, R.M., and J.R. Speakman. 1994. Central limits to sustainable metabolic rate have no role in cold acclimation of the short-tailed field vole (Microtus agrestis). Physiological Zoology 67:

$410 \quad 1117-1139$.

McKechnie, A.E. 2008. Phenotypic flexibility in basal metabolic rate and the changing view of avian physiological diversity: a review. Journal of Comparative Physiology B 178: 235-247. 
McKechnie, A.E., K. Chetty and B.G. Lovegrove. 2007. Phenotypic flexibility in the basal metabolic rate of laughing doves: responses to short-term thermal acclimation. Journal of

415 Experimental Biology 210: 97-106.

McNab, B.K. 2008. An analysis of the factors that influence the level and scaling of mammalian BMR. Comparative Biochemistry and Physiology A 151: 5-28.

McNab, B.K. 2009. Ecological factors affect the level and scaling of avian BMR. Comparative Biochemistry and Physiology A 152: 22-45.

420 McNab, B.K., and P. Morrison. 1963. Body temperature and metabolism in subspecies of Peromyscus from arid and mesic environments. Ecological Monographs 33: 63-82.

Meehan, T.D. 2006. Energy use and animal abundance in litter and soil communities. Ecology 87: 1650-1658.

Meehan, T.D., W. Jetz and J.H. Brown. 2004. Energetic determinants of abundance in winter 425 landbird communities. Ecology Letters 7: 532-537.

Meerlo, P., L. Bolle, G.H. Visser, D. Masman and S. Daan. 1997. Basal metabolic rate in relation to body composition and daily energy expenditure in the field vole, Microtus agrestis. Physiological Zoology: 362-369.

Mueller, P., and J. Diamond. 2001. Metabolic rate and environmental productivity: Well-

430 provisioned animals evolved to run and idle fast. Proceedings of the National Academy of Sciences 98: 12551-12554.

Munch, S.B., and S. Salinas. 2009. Latitudinal variation in lifespan within species is explained by the metabolic theory of ecology. Proceedings of the National Academy of Sciences 106: 1386013864.

435 Nespolo, R.F., Bacigalupe, E.L. Rezende and F. Bozinovic. 2001. When nonshivering thermogenesis equals maximum metabolic rate: Thermal acclimation and phenotypic plasticity of fossorial Spalacopus cyanus (Rodentia). Physiological and Biochemical Zoology 74: 325-332. Nilsson, J.Å. 2002. Metabolic consequences of hard work. Proceedings of the Royal Society of London B: Biological Sciences 269: 1735-1739.

440 Peterson, C.C., B.M. Walton and A.F. Bennett. 1998. Intrapopulation Variation in Ecological Energetics of the Garter Sanke Thamnophis sirtalis, with Analysis of the Precision of Doubly Labeled Water Measurements. Physiological and Biochemical Zoology 71: 333-349.

Portugal, S.J., J.A. Green, P. Cassey, P.B. Frappell and P.J. Butler. 2009. Predicting the rate of oxygen consumption from heart rate in barnacle geese Branta leucopsis: effects of captivity and

445 annual changes in body condition. Journal of Experimental Biology 212: 2941-2948.

Rezende, E.L., F. Gomes, M.A. Chappell and T. Garland Jr. 2009. Running Behavior and Its Energy Cost in Mice Selectively Bred for High Voluntary Locomotor Activity. Physiological and Biochemical Zoology 82: 662-679.

Ricklefs, R.E., M. Kornazewski and S. Daan. 1996. The relationship between basal metabolic rate 450 and daily energy expenditure in birds and mammals. The American Naturalist 147: 1047-1071. Ritchie, W., J. Green, P. Dann, P. Butler and P. Frappell. 2010. Do implanted data-loggers affect the time spent at sea by Little Penguins (Eudyptula minor) during winter? EMU 110: 71-77.

Signer, C., T. Ruf and W. Arnold. 2011. Hypometabolism and basking: the strategies of Alpine ibex to endure harsh over-wintering conditions. Functional Ecology 25: 537-547.

455 Signer, C., T. Ruf, F. Schober, G. Fluch, T. Paumann and W. Arnold. 2010. A versatile telemetry system for continuous measurement of heart rate, body temperature and locomotor activity in freeranging ruminants. Methods in Ecology and Evolution 1: 75-85.

Smit, B., and A.E. McKechnie. 2010. Avian seasonal metabolic variation in a subtropical desert: basal metabolic rates are lower in winter than in summer. Functional Ecology 24: 330-339.

460 Speakman, J., T. Ergon, R. Cavanagh, K. Reid, D. Scantlebury and X. Lambin. 2003. Resting and daily energy expenditures of free-living field voles are positively correlated but reflect extrinsic rather than intrinsic effects. Proceedings of the National Academy of Sciences 100: 14057-14062. Speakman, J.R. 2000. The cost of living: Field metabolic rates of small mammals. Advances in Ecological Research 30: 177-297. 
465 Speakman, J.R., and E. Król. 2010. Maximal heat dissipation capacity and hyperthermia risk: neglected key factors in the ecology of endotherms. Journal of Animal Ecology 79: 726-746. Tieleman, B.I., T.H. Dijkstra, K.C. Klasing, G.H. Visser and J.B. Williams. 2008. Effects of experimentally increased costs of activity during reproduction on parental investment and selfmaintenance in tropical house wrens. Behavioural Ecology 19: 949.

470 Tinbergen, J.M., and M.W. Dietz. 1994. Parental energy expenditure during brood rearing in the Great Tit (Parus major) in relation to body mass, temperature, food availability and clutch size. Functional Ecology 8: 563-572.

Turbill, C., T. Ruf, T. Mang and W. Arnold. 2011. Regulation of heart rate and rumen temperature in red deer: effects of season and food intake. Journal of Experimental Biology 214: 963-970.

475 Vézina, F., J.R. Speakman and T.D. Williams. 2006. Individually variable energy management strategies in relation to energetic costs of egg production. Ecology 87: 2447-2458.

Ward, S., C.M. Bishop, A.J. Woakes and P.J. Butler. 2002. Heart rate and the rate of oxygen consumption of flying and walking barnacle geese (Branta leucopsis) and bar-headed geese (Anser indicus). Journal of Experimental Biology 205: 3347-3356.

480 Weathers, W.W., D.C. Paton and R.S. Seymour. 1996. Field metabolic rate and water flux of nectarivorous honeyeaters. Australian Journal of Zoology 44: 445-460.

West, G.C. 1972. Seasonal differences in resting metabolic rate of Alaskan ptarmigan. Comparative Biochemistry and Physiology A 42: 867-876.

White, C.R., T.M. Blackburn, G.R. Martin and P.J. Butler. 2007. Basal metabolic rate of birds is 485 associated with habitat temperature and precipitation, not primary productivity. Proceedings of the Royal Society B 274: 287-293.

White, C.R., D. Gremillet, J.A. Green, G. Martin and P.J. Butler. 2011. Metabolic rate throughout the annual cycle reveals the demands of an Arctic existence in great cormorants. Ecology 92: 475486.

490 White, C.R., and R.S. Seymour. 2004. Does BMR contain a useful signal? Mammalian BMR allometry and correlations with a selection of physiological, ecological and life-history variables. Physiological and Biochemical Zoology 77: 929-941. 
Table 1. Results of simple linear regressions between qualitative and quantitative proxies of resting metabolic rate (min $\dot{V}_{\mathrm{O}_{2}}$ or $f_{\mathrm{H}}$ ), daily metabolic rate (mean $\dot{V}_{\mathrm{O}_{2}}$ or $f_{\mathrm{H}}$ ), and activity metabolic rate (activity $\dot{V}_{\mathrm{O}_{2}}$ or $f_{\mathrm{H}}$ ) in eleven species of free-ranging birds and mammals. Correlations indicating some degree of evidence of a relationship are indicated in bold. Also shown are the number of animals from which data were analysed (N), the length of the data set in days (duration), the autocorrelation, and the resultant number of data points used in the analysis for each species (n). Values in square brackets are bias corrected accelerated $95 \%$ confidence intervals (CI) based on 10000 bootstrapped iterations.

\begin{tabular}{|c|c|c|c|c|c|c|c|c|c|c|c|c|c|c|}
\hline \multirow[b]{2}{*}{ Species } & & \multicolumn{4}{|c|}{ Mean $\dot{V}_{\mathrm{O}_{2}} \sim \min \dot{V}_{\mathrm{O}_{2}}$} & \multicolumn{4}{|c|}{ Activity $\dot{V}_{\mathrm{O}_{2}} \sim \min \dot{V}_{\mathrm{O}_{2}}$} & \multirow[b]{2}{*}{ Model supported } & \multirow[b]{2}{*}{$\mathrm{N}$} & \multirow[b]{2}{*}{ Duration } & \multirow{2}{*}{$\begin{array}{c}\text { Auto- } \\
\text { correlation }\end{array}$} & \multirow[b]{2}{*}{$\mathrm{n}$} \\
\hline & & slope & {$[95 \% \mathrm{CI}]$} & $r^{2}$ & $P$ & slope & {$[95 \% \mathrm{CI}]$} & $r^{2}$ & $P$ & & & & & \\
\hline Great Cormorant & G & 1.12 & {$[0.55,1.64]$} & 0.66 & 0.001 & 0.12 & {$[-0.50,0.63]$} & 0.02 & 0.63 & Independent & 7 & 172 & 14 & 13 \\
\hline $\begin{array}{l}\text { Barnacle Goose } \\
\text { Australasian }\end{array}$ & B & 1.12 & {$[0.88,1.32]$} & 0.91 & $<0.001$ & 0.15 & {$[-0.07,0.34]$} & 0.17 & 0.12 & Independent & 6 & 361 & 23 & 16 \\
\hline Gannet & A & 1.25 & {$[1.01,1.38]$} & 0.82 & $<0.001$ & 0.26 & {$[-0.02,0.41]$} & 0.16 & 0.11 & Independent & 6 & 237 & 14 & 17 \\
\hline Little Penguin & $\mathrm{L}$ & 1.22 & {$[0.89,1.39]$} & 0.86 & $<0.001$ & 0.21 & {$[-0.17,0.41]$} & 0.15 & 0.08 & Independent/Performance & 5 & 208 & 10 & 21 \\
\hline King Penguin & K & $* 0.58$ & {$[0.14,0.66]$} & 0.83 & 0.01 & $* 0.38$ & {$[-2.15,0.89]$} & 0.08 & 0.32 & Independent & 6 & 30 & 2 & 15 \\
\hline Macaroni Penguin & M & 1.33 & {$[1.08,1.75]$} & 0.88 & $<0.001$ & 0.33 & {$[0.09,0.76]$} & 0.31 & 0.03 & Performance & 63 & 730 & 49 & 15 \\
\hline \multirow[t]{3}{*}{ Eider Duck } & $\mathrm{E}$ & 1.06 & {$[0.82,1.49]$} & 0.74 & $<0.001$ & 0.12 & {$[-0.14,0.53]$} & 0.03 & 0.52 & Independent & 13 & 220 & 13 & 16 \\
\hline & & \multicolumn{4}{|c|}{ Mean $\mathrm{fH} \sim \min \mathrm{fH}$} & \multicolumn{4}{|c|}{ Activity $\mathrm{fH} \sim \min \mathrm{fH}$} & & & & & \\
\hline & & slope & {$[95 \% \mathrm{CI}]$} & $r^{2}$ & $P$ & Slope & {$[95 \% \mathrm{CI}]$} & $r^{2}$ & $P$ & & & & & \\
\hline Przewalski Horse & $\mathrm{P}$ & 1.17 & {$[1.08,1.49]$} & 0.97 & $<0.001$ & 0.17 & {$[0.11,0.35]$} & 0.41 & 0.01 & Performance & 7 & 371 & 24 & 17 \\
\hline Alpine Ibex & A & 1.13 & {$[1.04,1.31]$} & 0.98 & $<0.001$ & 0.14 & {$[0.06,0.25]$} & 0.40 & 0.01 & Performance & 20 & 348 & 48 & 15 \\
\hline Red Deer & $\mathrm{R}$ & 1.07 & {$[1.04,1.09]$} & 1.00 & $<0.001$ & 0.08 & {$[0.05,0.11]$} & 0.56 & $<0.001$ & Performance & 15 & 771 & 24 & 24 \\
\hline
\end{tabular}


Roe Deer

RO

$1.2 \quad[1.05,1.34]$

$0.83<0.001$

$0.19[0.04,0.32]$

0.110 .03

Performance

$14 \quad 1254$

30 45 relationship. The way the exponent is interpreted is the same as for the linear relationships exhibited by all the other species. 

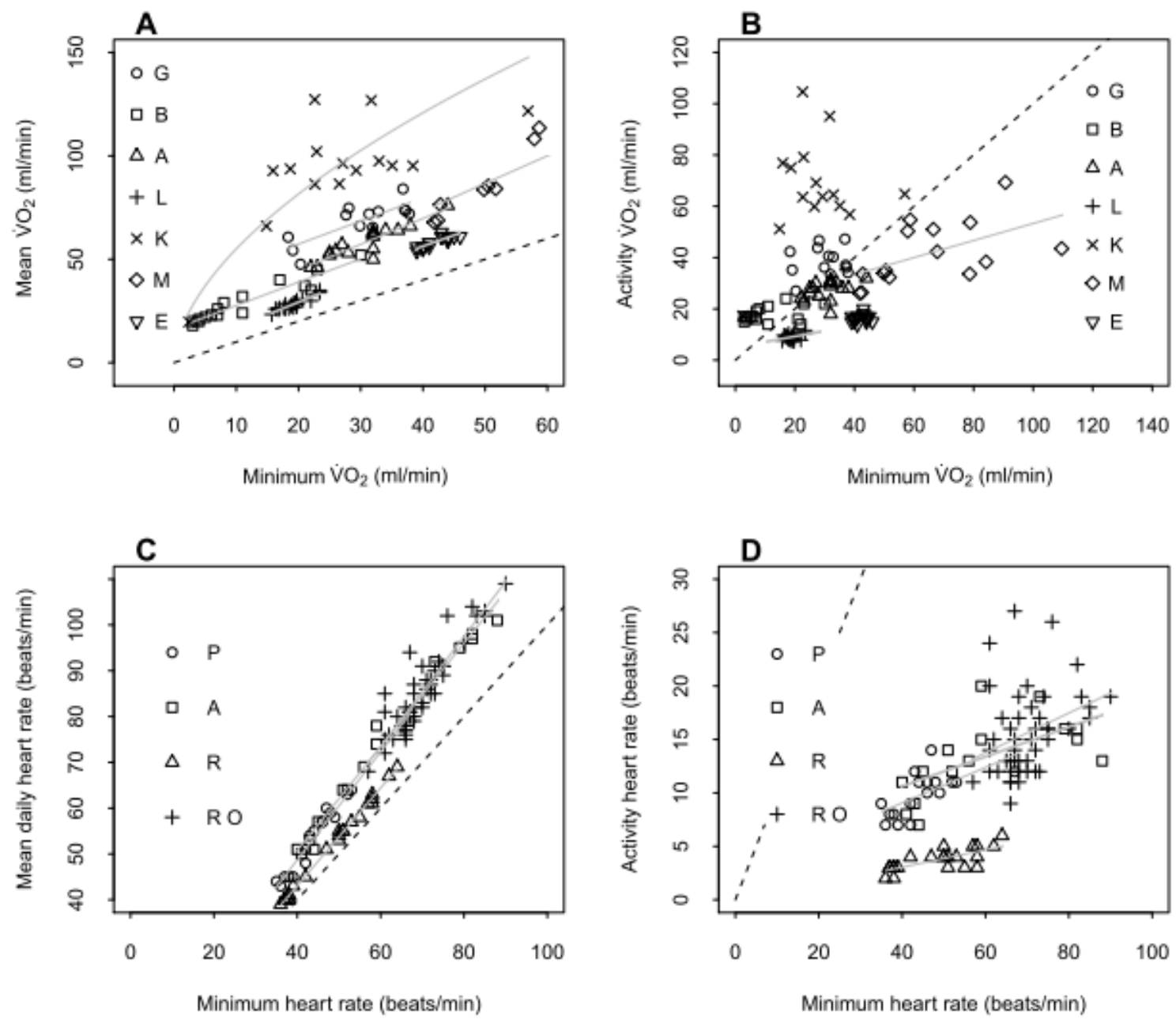

Figure 1. Relationships between qualitative and quantitative proxies of metabolic rate (A and B) in seven species of birds and between measures of heart rate (C and D) in four species of mammal. Explanations for each measure are provided in the main text. Evidence for correlations are indicated by the presence of best fit lines (all data points in panels A, C and D have best fit lines; the line for little penguins in panel B has been extended for clarity). Some data points are obscured behind others. The y axis of panel $\mathrm{C}$ does not include 0 . In each panel, the slope of unity is presented as a dashed line. See Table 1 for species name 515 abbreviations. 


\section{APPENDIX - QUALITATIVE ANALYSIS OF METABOLIC RATES IN BIRDS}

We repeated the analysis between RMR, AEE and DEE using heart rate (min fH, activity fH and mean $\mathrm{fH}$, respectively) for the seven bird species under consideration. For most correlations for the seven species of bird, the conclusion does not change whether interpreting the data quantitatively ( $\dot{V}_{\mathrm{O}_{2}}$ data) or qualitatively (fH data); Table A1. However, the relationship between activity $\mathrm{fH}$ and $\min \mathrm{fH}$ for Australasian gannets is significantly negative. This is a product of the curvilinear relationship between $\dot{V}_{\mathrm{O}_{2}}$ and fH (Green et al. 2013) and the greater proportion of the day spent in flight by this species (25-35\%; Green et al 2013) compared to the other volant bird species included in the present study (usually $<5 \%$; Grémillet et al. 2005; Pelletier et al. 2008; Portugal et al. 2012). For any species, a curvilinear relationship results in the difference in heart rate between min $\mathrm{fH}$ and mean $\mathrm{fH}$ equating to a greater difference in $\dot{V}_{\mathrm{O}_{2}}$ at higher heart rates than at lower heart rates. However for the geese, eider and cormorants there is no difference in interpretation between the qualitative and quantitative analyses since on a typical day, high heart rates associated with

530 flight are rarely recorded. In contrast, for the gannets the high heart rates associated with flight are often recorded and these have a disproportionately large effect on DEE. Thus the lack of a relationship between AEE and RMR in Australasian gannets presents as a negative relationship between activity $\mathrm{fH}$ and $\mathrm{min} \mathrm{fH}$. Overall this then supports the use of the quantitative approach where possible, since it incorporates the maximum amount of

535 information that we have about the respiratory and cardiovascular physiology of these birds. While $\dot{V}_{\mathrm{O}_{2}}-\mathrm{fH}$ calibrations were not available for the four mammal species in this study, calibrations for other terrestrial mammals have been reported as linear relationships (Green 2011). Assuming this holds for the mammal species presently under consideration, we would expect the conclusions formed from the fH relationships to hold for those data when converted to $\dot{V}_{\mathrm{O}_{2}}$. 
Table 1A. Results of simple linear regressions between qualitative proxies of resting metabolic rate (min $f_{\mathrm{H}}$ ), daily metabolic rate $\left(\right.$ mean $\left.f_{\mathrm{H}}\right)$, and activity metabolic rate (activity $f_{\mathrm{H}}$ ) in seven species of free-ranging birds. Correlations indicating some degree of evidence of a relationship are indicated in bold. Also shown are the number of animals from which data were analysed $(\mathrm{N})$, the length of the data set in days (duration), the autocorrelation, and the resultant number of data points used in the analysis for each species (n). Values in square brackets are bias corrected accelerated $95 \%$ confidence intervals (CI) based on 10000 bootstrapped iterations.

\begin{tabular}{|c|c|c|c|c|c|c|c|c|c|c|c|c|c|c|}
\hline \multirow[b]{2}{*}{ Species } & & \multicolumn{4}{|c|}{ Mean $\mathrm{fH} \sim \min \mathrm{fH}$} & \multicolumn{4}{|c|}{ Activity $\mathrm{fH} \sim \min \mathrm{fH}$} & \multirow[b]{2}{*}{ Model supported } & \multirow[b]{2}{*}{$\mathrm{N}$} & \multirow[b]{2}{*}{ Duration } & \multirow[b]{2}{*}{$\begin{array}{c}\text { Auto- } \\
\text { correlation }\end{array}$} & \multirow[b]{2}{*}{$\mathrm{n}$} \\
\hline & & slope & {$[95 \% \mathrm{CI}]$} & $r^{2}$ & $P$ & slope & {$[95 \% \mathrm{CI}]$} & $r^{2}$ & $P$ & & & & & \\
\hline Great Cormorant & $\mathrm{G}$ & 0.83 & {$[0.47,1.14]$} & 0.70 & $<0.001$ & -0.17 & {$[-0.54,0.15]$} & 0.08 & 0.34 & Independent & 7 & 172 & 14 & 13 \\
\hline $\begin{array}{l}\text { Barnacle Goose } \\
\text { Australasian }\end{array}$ & $\mathrm{B}$ & 1.13 & {$[0.91,1.31]$} & 0.92 & $<0.001$ & 0.13 & {$[-0.09,0.32]$} & 0.13 & 0.17 & Independent & 6 & 361 & 23 & 16 \\
\hline Gannet & A & 0.66 & {$[0.53,0.75]$} & 0.79 & $<0.001$ & -0.33 & {$[-0.46,-0.25]$} & 0.49 & $<0.01$ & & 6 & 237 & 14 & 17 \\
\hline Little Penguin & $\mathrm{L}$ & 1.21 & {$[0.90,1.40]$} & 0.86 & $<0.001$ & 0.23 & {$[-0.10,0.41]$} & 0.18 & 0.06 & Independent/Performance & 5 & 208 & 10 & 21 \\
\hline King Penguin & $\mathrm{K}$ & 1.04 & {$[0.27,1.36]$} & 0.67 & $<0.001$ & 0.04 & {$[-0.75,0.36]$} & 0.00 & 0.85 & Independent & 6 & 30 & 2 & 15 \\
\hline Macaroni Penguin & M & 1.33 & {$[1.06,1.79]$} & 0.87 & $<0.001$ & 0.33 & {$[0.08,0.76]$} & 0.31 & 0.03 & Performance & 63 & 730 & 49 & 15 \\
\hline Eider Duck & $\mathrm{E}$ & 1.08 & {$[0.79,1.50]$} & 0.68 & $<0.001$ & 0.05 & {$[-0.28,0.59]$} & 0.00 & 0.81 & Independent & 13 & 220 & 13 & 16 \\
\hline
\end{tabular}



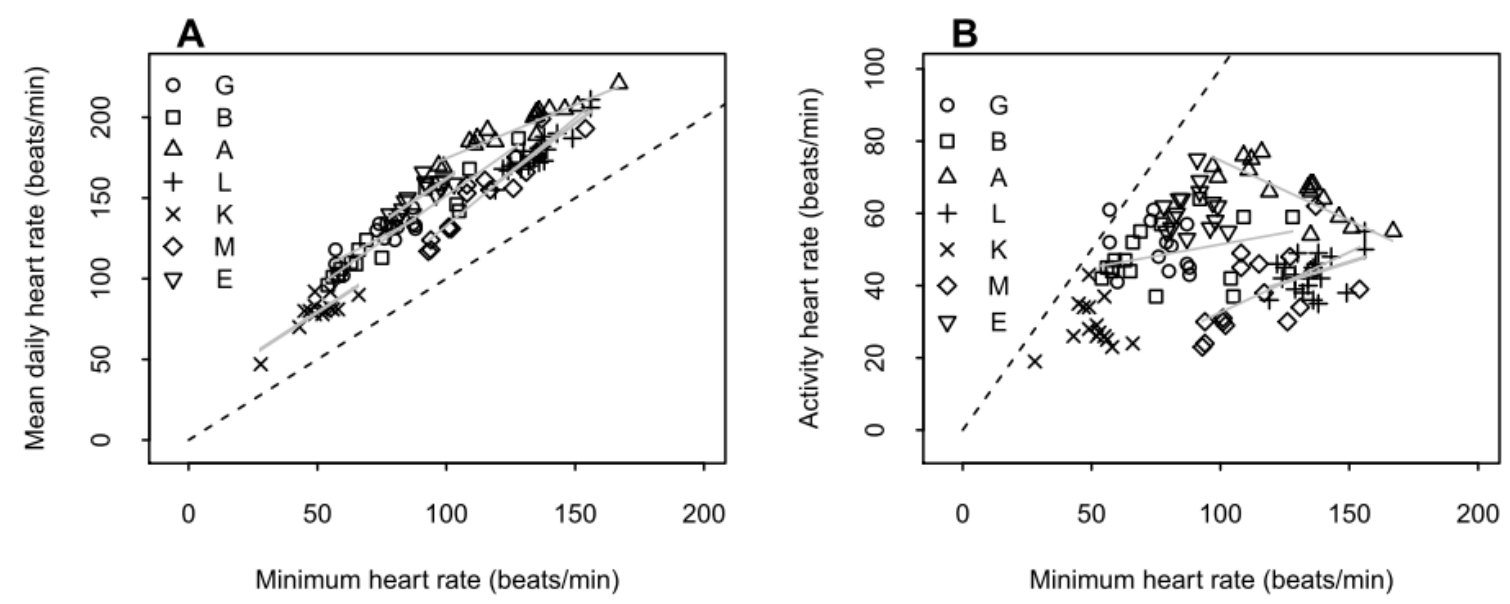

Figure A1. Relationships between qualitative proxies of metabolic rate in seven species of birds. Evidence for correlations are indicated by the presence of best fit lines (all data points in panel A have best fit lines). Some data points are obscured behind others. In each panel, the slope of unity is presented as a dashed line. See Table A1 for species name abbreviations.

555 Grémillet, D., G. Kuntz, A.J. Woakes, C. Gilbert, J.-P. Robin, Y. Le Maho and P.J. Butler. 2005. Year-round recordings of behavioural and physiological parameters reveal the survival strategy of a poorly insulated diving endotherm during the Arctic winter. Journal of Experimental Biology 208: 4231-4241.

Pelletier, D., M. Guillemette, J.-M. Grandbois and P.J. Butler. 2008. To fly or not to fly: high 560 flight costs in a large sea duck do not imply an expensive lifestyle. Proceedings of the Royal Society of London B: Biological Sciences 275: 2117-2124.

Portugal, S.J., J.A. Green, C.R. White, M. Guillemette and P.J. Butler. 2012. Wild geese do not increase flight behaviour prior to migration. Biology Letters 8: 469-472. 